\title{
Production of moth sex pheromone precursors in Nicotiana spp.: a worthwhile new approach to pest control
}

\author{
Yi-Han Xia $^{1}$ - Bao-Jian Ding ${ }^{1} \cdot$ Hong-Lei Wang ${ }^{1} \cdot$ Per Hofvander ${ }^{2} \cdot$ Carin Jarl-Sunesson $^{1} \cdot$ Christer Löfstedt $^{1}$
}

Received: 5 December 2019 / Revised: 22 April 2020 / Accepted: 6 June 2020 / Published online: 19 June 2020

(c) The Author(s) 2020

\begin{abstract}
Pheromones are environmentally friendly alternatives to traditional pesticides for pest control. They are widely applied for insect monitoring, mating disruption and mass trapping. Nicotiana benthamiana and N. tabacum are potential green biomass production platforms of moth sex pheromones. Using these two Nicotiana species as plant factories, we expressed biosynthetic genes of plant and insect origin in leaf tissue. Moth sex pheromone precursors $(E)$-11-tetradecenoic acid, $(Z)$ 11-tetradecenoic acid and (Z)-11-hexadecenoic acid were produced by introducing the acyl-ACP thioesterases CpuFatB1 from Cuphea pulcherrima or CpaFatB2 from C. palustris and the fatty acyl desaturases Ave $\Delta 11$ from Argyrotaenia velutinana, CpaE11 from Choristoneura parallela or Atr $\Delta 11$ from Amyelois transitella, under the control of CaMV-35S promoter. Among the Nicotiana spp. transformants, the best line produced $(Z)$-11-hexadecenoic acid at $17.6 \%$ of total fatty acids in leaves, during flowering stage, corresponding to $335 \mu \mathrm{g}$ of (Z)-11-hexadecenoic acid per gram of fresh leaf. The (Z)-11hexadecenoic acid production lines from $N$. benthamiana were selected for further propagation to obtain homozygous lines. In the $N$. benthamiana $\mathrm{T} 2$ generation, the production quantity of (Z)-11-hexadecenoic acid was stable. Our study demonstrates the feasibility of stable transformation of $N$. benthamiana for production of moth pheromone precursors in vegetative tissue.
\end{abstract}

Keywords Pest control $\cdot$ Insect pheromone precursors · Nicotiana spp. · Acyl-ACP thioesterase · Fatty acyl desaturase ·

Stable transformation

\section{Key message}

- Pheromones are environmentally friendly alternatives to traditional pesticides for pest control. We established a novel approach to produce moth pheromone precursors stably.

Communicated by P. G. Becher.

Electronic supplementary material The online version of this article (https://doi.org/10.1007/s10340-020-01250-6) contains supplementary material, which is available to authorized users.

Yi-Han Xia

yihan.xia@biol.lu.se

1 Department of Biology, Lund University, Sölvegatan 37, 22362 Lund, Sweden

2 Department of Plant Breeding, Swedish University of Agricultural Sciences, P.O. Box 101, 23053 Alnarp, Sweden
- This is the first report on production of insect pheromone precursors over generations in plants.

- We produced (E)-11-tetradecenoic acid, (Z)-11-tetradecenoic acid and $(Z)$-11-hexadecenoic acid, the fatty acid precursors of pheromones used by hundreds of moth pest species.

- Worthwhile amounts of (Z)-11-hexadecenoic acid may be produced by cultivating our most productive $N$. benthamiana line under field conditions.

\section{Introduction}

The insect order Lepidoptera contains more than 160,000 described moth and butterfly species (Nieukerken et al. 2011). Species of moths are among the most damaging pests of food and fiber crops. Moths also have the capability of adapting fast and evolving resistance to insecticides (Simmons et al. 2010). Female moths emit species-specific sex pheromone component blends that attract males of the same species over long distances for mating (Wyatt 2003). 
Due to the numerous problems associated with use of conventional pesticides (Brittain and Potts 2011; Bull 1982), synthetic pheromones have emerged as an alternative for insect control (Reddy and Guerrero 2000). Currently, tons of synthetic pheromones are produced for application in pest management (Weatherston and Stewart 2002). However, use of hazardous chemicals and generation of by-products during conventional chemical synthesis of pheromones (Mori 2007, 2010) may cause pollution problems. High costs for synthesis also limit the use of pheromones in many crops.

Since the techniques for genetically engineering of plants were developed in the early 1980 s, numerous research projects have focused on utilizing transgenic plants to produce high-value recombinant proteins or compounds (Boehm 2007; Karg and Kallio 2009; Lienard et al. 2007; Ma et al. 2005; Mett et al. 2008). During the past 20 years, producing insect pheromones or their biosynthetic precursors in genetically modified plant factories has been attempted. A moth pheromone precursor was produced in Nicotiana tabacum by the introduction of a moth desaturase (Nešněrová et al. 2004), and an aphid alarm pheromone was produced from endogenous plant sesquiterpene by expression of a $(E)-\beta$ farnesene synthase in Arabidopsis (Beale et al. 2006). Moreover, Ding et al. (2014) proved that transient expression of genes coding for consecutive pheromone biosynthetic steps in $N$. benthamiana resulted in production of biologically active multi-component sex pheromones. The sex pheromone mixtures prepared from the acetylated fatty alcohol fractions produced by the genetically modified plants has the same activity for trapping of male small ermine moths Yponomeuta evonymella and Y. padella compared to conventionally produced synthetic pheromones (Ding et al. 2014). These studies have demonstrated that it is feasible to produce highly attractive and species-specific moth pheromones in genetically modified plants. However, the use of stably transformed $N$. benthamiana for semi-synthetic preparation of pheromones was so far never explored.

The majority of known moth pheromones are unsaturated $\mathrm{C}_{10}-\mathrm{C}_{18}$ straight chain primary alcohols, acetates or aldehydes (Ando et al. 2004; Löfstedt et al. 2016). The biosynthesis of these compounds starts from de novo synthesis of palmitic acid or stearic acid, followed by desaturation, chain elongation or shortening to produce specific chain lengths, double bond positions and stereochemistry and finally the formation of the terminal functional groups (Löfstedt et al. 2016). In plant leaf tissue, the fatty acid biosynthesis takes place primarily in the chloroplasts utilizing $\mathrm{C} 3$ products of photosynthesis as carbon source (Bao et al. 2000). The palmitic and oleic acids so produced are then released into the cytosol as precursors for extra-plastid lipid synthesis and provide a pool of substrates that pheromone biosynthetic enzymes might utilize for moth pheromone production. Furthermore, the enzymes deployed for the biosynthesis of extra-plastid lipids and the insect desaturases introduced for the biosynthesis of moth pheromones in this study are located in the endoplasmic reticulum (Heinemann and Ozols 2003; Li et al. 2013), which also offers advantages for producing moth pheromones in plant leaves.

Nicotiana spp. are suitable to use for lipid metabolic engineering as they can be transformed by Agrobacterium with relative ease and high efficiency as well as having a fairly large green biomass (Aslan et al. 2014; Naim et al. 2012; Reynolds et al. 2015). In the present study, we used genes for Nicotiana spp. transformation that have been functionally characterized in heterologous expression systems in previous studies. These genes include: two plastid acylACP thioesterases, CpuFatBI from Cuphea pulcherrima (Myrtales: Lythraceae) (Kim et al. 2015a) and CpaFatB2 from C. palustris (Dehesh et al. 1996a) that can increase the amount of palmitic acid and myristic acid, respectively, by hydrolyzing the thioester bond of acyl-chain-ACP synthesized by the fatty acid synthase complex; three $\Delta 11$ fatty acyl desaturases, i.e., Ave $\Delta 11$ from Argyrotaenia velutinana (Lepidoptera: Tortricidae) and CpaE11 from Choristoneura parallela (Lepidoptera: Tortricidae) producing (Z)-11tetradecenoic acid (Z11-14:acid) (Liu et al. 2002) and (E)11-tetradecenoic acid (E11-14:acid) (Liu et al. 2004), and Atr 11 from Amyelois transitella (Lepidoptera: Pyralidae) producing (Z)-11-hexadecenoic acid (Z11-16:acid) (Ding et al. 2014). We used Agrobacterium-mediated leaf-disc stable transformation (Clemente 2006) on N. tabacum to allow pheromone precursors Z11-14:acid, E11-14:acid and Z1116:acid production. The three pheromone precursors were produced in all regenerated transformants. Subsequently, the same set of genes were introduced into $N$. benthamiana. We then propagated and selected $N$. benthamiana lines for the production of Z11-16:acid, an immediate pheromone precursor for many moth species (Ando et al. 1979; Kehat and Dunkelbum 1990; Lynch et al. 1984; Rothschild et al. 1982). Our study proves the feasibility to produce a high quantity of moth pheromone precursors in stably transformed plants.

\section{Materials and methods}

\section{Construction of plant expression vectors for tobacco stable transformation}

CpaFatB2 (GeneBank accession number: AAC49180),

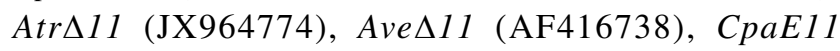
(AF518014) were amplified from entry clones (Ding et al. 2014). CpuFatB1 (AGG79283) was a gift from E. Cahoon (University of Nebraska, Lincoln). Cauliflower mosaic virus $35 \mathrm{~S}$ promoter $(35 \mathrm{~S})$ and Octopine Synthase gene terminator $(O C S)$ were used to regulate gene expression. For assembling multiple genes into one expression cassette, each gene, 
including promoter and terminator, was first amplified by PCR, with primers (Table S1) spanning from the start codon to the stop codon of the opening reading frame (ORF), on a Veriti Thermo Cycler. The conditions used were: $95{ }^{\circ} \mathrm{C}$ for 5 min, 35 cycles of $95^{\circ} \mathrm{C}$ for $30 \mathrm{~s}, 55^{\circ} \mathrm{C}$ for $40 \mathrm{~s}, 72^{\circ} \mathrm{C}$ for $1 \mathrm{~min}$, followed by a final extension for $10 \mathrm{~min}$ at $72^{\circ} \mathrm{C}$. The reactions were performed in a total volume of $50 \mu \mathrm{L}$, containing $25 \mu \mathrm{L}$ of Maxima polymerase master mix (Thermo Scientific $\left.{ }^{\mathrm{TM}}\right), 2.5 \mu \mathrm{L}$ for each primer $(10 \mu \mathrm{M})$ (Table S1), 1 $\mu \mathrm{L}$ of sample cDNA $(15 \mathrm{ng} / \mu \mathrm{L}), 19 \mu \mathrm{L}$ of sterilized $\mathrm{H}_{2} \mathrm{O}$. The PCR products were analyzed by electrophoresis on $1.5 \% \mathrm{w} / \mathrm{v}$ agarose gel in TAE buffer $(40 \mathrm{mM}$ Tris-acetate, $2 \mathrm{mM} \mathrm{Na}_{2}$ EDTA- $\mathrm{H}_{2} \mathrm{O}$ ), and gel purified with a GeneJET Gel Extraction Kit (Thermo Scientific ${ }^{\mathrm{TM}}$ ). Subsequently, fusion PCR (phusion ${ }^{\circledR}$ Taq, Thermo Scientific) was used to perform truncation and gene fusion for gene assembly (Atanassov et al. 2009). All genes with promoters and terminators were cloned into plant expression vector pXZP393 by Gateway recombination cloning technology (Invitrogen).

\section{Assembly of moth pheromone biosynthetic pathways}

Three plant expression vectors (Fig. 1a) were constructed to produce different pheromone precursors by assembling various transgene combinations. The expression of the exogenous genes was controlled by the $35 \mathrm{~S}$ promoter (Gatz et al. 1992) and OCS terminator (Schünmann et al. 2003). The engineered pathways for pheromone precursors production are shown in Fig. 1b. The thioesterases encoded by CpaFatB2 and CpuFatB1 take the myristate and palmitate plastid acyl carrier protein (ACP) from chain elongation, respectively, to form the corresponding myristic (14:0) (Dehesh et al. 1996) and palmitic (16:0) acid (Kim et al. 2015). The fatty acids are acylated to $14: \mathrm{CoA}$ and 16:CoA when transported out of the plastid into the cytosol. The 14:CoA and 16:CoA are then subsequently converted into the corresponding pheromone precursors Z11-14:CoA, E11-14:CoA and Z11-16:CoA, by a desaturase encoded by

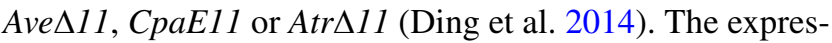
sion vector with the functional transgene combination of CpuFatB1-Atr $\Delta 11$ was transformed both into N. tabacum and $N$. benthamiana, cultivating the line for production of Z11-16:CoA. The other expression vectors that contained CpaFatB2-Ave $\Delta 11$ or CpaFatB2-CapE11 were only transformed into $N$. tabacum, cultivating two different lines for production of Z11-14:CoA and E11-14:CoA, or E1114:CoA alone, respectively.

\section{Plant material and growth condition}

Wild-type $N$. benthamiana, wild-type $N$. tabacum (Wisconsin 38) and transgenic plants were grown either in the

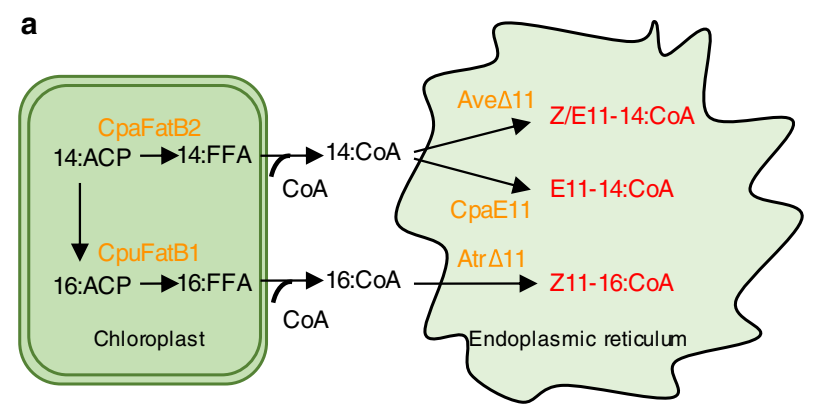

b
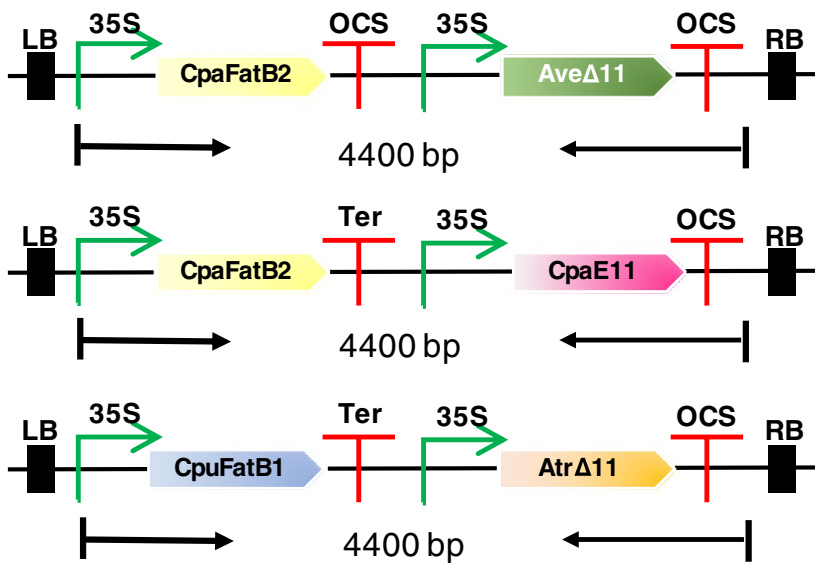

Fig. 1 Engineering strategy toward pheromone precursor production in Nicotiana spp. a Scheme of expression vectors for pheromone precursor production in Nicotiana spp. by stable transformation. pXZP393, plant expression vector pXZP393. 35S, Cauliflower mosaic virus $35 \mathrm{~S}$ promoter. OCS, Octopine Synthase gene terminator. Pheromone biosynthetic genes are shown in bold. RB and LB are the T-DNA border sequences for Agrobacterium which are shown in black background. The sequence length between RB and LB is ca. 4400 bp. CpaFatB2, Cuphea palustris 14:ACP thioesterase; CpuFatB1, C. pulcherrima 16:ACP thioesterase; Ave $\Delta 11$, Argyrotaenia velutinana $\Delta 11$ desaturase; CpaE11, Choristoneura parallela E11 desaturase; Atr $\Delta 11$, Amyelois transitella $\Delta 11$ desaturase. b Engineered metabolic pathways of pheromone precursor production in Nicotiana spp. leaves. ACP, acyl carrier protein; FFA, free fatty acids. The introduced enzymes are indicated in orange, and the target pheromone precursor is shown in red. Acyl intermediates in the pathway (also throughout the article) are given as short forms. E/Z11-14:CoA refers to the fatty acyl coenzyme A with a chain length of 14-carbon atoms and a double bond at $\Delta 11$ position in ' $E$ ' or ' $Z$ ' configuration; Z11-16:CoA refers to the fatty acyl coenzyme A with a chain length of 16-carbon atoms and a double bond at $\Delta 11$ positions in ' $\mathrm{Z}$ ' configuration

greenhouse under $16 \mathrm{~h} / 8 \mathrm{~h}$ or in a climate chamber under $14 \mathrm{~h} / 10 \mathrm{~h}$ light/dark conditions. Growth temperature and relative humidity in greenhouse were set at $24{ }^{\circ} \mathrm{C} / 18{ }^{\circ} \mathrm{C}$ in day/night and $40 \%$, respectively. In the climate chamber, the temperature was set at $22{ }^{\circ} \mathrm{C}$. 


\section{Transformation of Agrobacterium}

All the constructed expression clones in pXZP393 were confirmed by sequencing and then electroporated into A. tumefaciens GV3101 (MP90RK) with settings of $1700 \mathrm{Vmm}^{-1}$, $5 \mathrm{~ms}$ (Eppendorf 2510).

\section{Agrobacterium-mediated leaf-disc transformation}

For each construct, $30 \mathrm{ml}$ of Agrobacterium solution was incubated at $30{ }^{\circ} \mathrm{C}$ in LB medium supplemented with $50 \mathrm{mg} / \mathrm{L}$ rifampicin, $50 \mathrm{mg} / \mathrm{L}$ gentamicin and $50 \mathrm{mg} / \mathrm{L}$ spectinomycin for $24 \mathrm{~h}\left(30^{\circ} \mathrm{C}, 300 \mathrm{rpm}\right.$ (INNOVA ${ }^{\circledR} 42$, Incubator Shaker Series)). The bacteria were spun down at 3,300 g for $5 \mathrm{~min}$ at room temperature and resuspended in LB medium without any antibiotic. Optical density (A600nm) of each Agrobacterium culture was adjusted to $0.9-1$ in a total volume of $30 \mathrm{ml}$ with LB medium prior to tobacco leaf-disc transformation. Plant material was obtained from 4-5-weekold Nicotiana plants grown under sterile conditions on MS medium (Murashige and Skoog 1962) in a climate chamber.

Transgenic lines were obtained by Agrobacterium-mediated leaf-disc transformation. Leaf discs $(20 \mathrm{~mm} \times 20 \mathrm{~mm})$ were cut out and incubated $5 \mathrm{~min}$ in an A. tumefaciens solution, dried with sterile napkin paper and transferred to Petri dishes with MS medium (Horsch el al. 1985). After $48 \mathrm{~h}$ incubation in darkness, leaf discs were transferred to selection medium (MS medium supplemented with $50 \mathrm{mg} / \mathrm{L}$ kanamycin, $250 \mathrm{mg} / \mathrm{L}$ cefotaxime, $1 \mathrm{mg} / \mathrm{L}$ 6-benzylaminopurine (BAP) and $0.1 \mathrm{mg} / \mathrm{L}$ naphthalene acetic acid (NAA)). After 2-3 weeks of incubation, the calli produced on the leaf edges were transferred to shoot-inducing medium (the selection medium supplemented with $100 \mathrm{mg} / \mathrm{L}$ kanamycin). After 2-3 weeks of incubation, the shoots were transferred to rootinducing medium (identical as shoot-inducing medium, but without hormones) with $100 \mathrm{mg} / \mathrm{L}$ kanamycin and $250 \mathrm{mg} / \mathrm{L}$ cefotaxime. The shoots were finally transferred into soil and grown in greenhouse until maturity.

\section{Sampling for leaf lipids analysis}

The T0 plants regenerated from calli were used for lipid analysis. From each T0 plant at the age of 1.5 months, three pieces of different mature leaves (size ca. $50 \mathrm{~mm} \times 50 \mathrm{~mm}$ ) were randomly taken. Samples from each T0 plant were analyzed in triplicate. Then, the $\mathrm{T} 0$ plants were kept growing in greenhouse until maturity of T1 seeds. Subsequently, T1 seeds collected from the best target compound-producing T0 plant were sown on MS medium supplemented with $100 \mathrm{mg} / \mathrm{L}$ kanamycin. For $N$. tabacum and N. benthamiana, eight and thirty T1 plants from each T0 plant were cultivated, respectively. Seedlings from each T1 plant surviving the selection were transferred to soil and grown to maturity for producing T2 seeds. Thirty $N$. benthamiana T2 seeds from each plant were collected and cultivated to T2 plants for analysis. For T1 and T2 plant analysis, at the same age to $\mathrm{T} 0$ plant, three pieces of mature leaves (size was same to T0 plant) were randomly taken from each plant and mixed as one sample.

\section{Total fatty acids analysis}

For fatty acid analysis, 100-300 mg fresh leaf tissue per sample was treated by $1 \mathrm{~mL} 2 \%$ sulfuric acid in methanol containing $3.12 \mu \mathrm{g}$ methyl nonadecanoate (19:Me) as internal standard, incubated at $90^{\circ} \mathrm{C}$ for $1 \mathrm{~h}$. Subsequently, $1 \mathrm{~mL}$ water and $1 \mathrm{~mL}$ heptane were added and the mixture was vigorously vortexed and centrifuged at $2000 \mathrm{rpm}$ (Heraeus ${ }^{\mathrm{TM}}$ Sepatech-3760) for $2 \mathrm{~min}$. Finally, ca. $1 \mathrm{~mL}$ heptane phase containing the fatty acids in the form of corresponding methyl esters was transferred to a new glass vial for GC/ MS analysis.

\section{TLC separation of leaf neutral lipids}

For neutral lipid analysis, total lipids from $1 \mathrm{~g}$ fresh leaf were extracted in $4 \mathrm{~mL}$ of methanol/chloroform $(2: 1, \mathrm{v} / \mathrm{v})$ using a glass tissue grinder. The crude extract was transferred to a glass tube, and the grinder was washed with $1 \mathrm{~mL}$ of chloroform, which was then transferred to the extract. One milliliter of water was added to produce a biphasic mixture, which was then vortexed vigorously and centrifuged at $2000 \mathrm{rpm}$ (Heraeus ${ }^{\mathrm{TM}}$ Sepatech-3760) for $2 \mathrm{~min}$. Total leaf lipids extract was then present in ca. $2.3 \mathrm{~mL}$ chloroform phase. From this phase, $300 \mu \mathrm{L}$ was taken and concentrated to ca. $40 \mu \mathrm{L}$ under gentle nitrogen flow and then loaded at $20 \mathrm{~mm}$ from the bottom of a thin-layer chromatography (TLC) plate without fluorescent indicator (Silica gel 60, Merck, Germany), along with standard (TLC Mix 34, Larodan, Sweden). The plate was developed in a solvent system of heptane/diethyl ether/acetic acid (60:40:1, v/v/v). The obtained lipid bands were scraped off and extracted with $1.5 \mathrm{~mL}$ of methanol/chloroform $(2: 1, \mathrm{v} / \mathrm{v})$ containing $3.12 \mu \mathrm{g}$ 19:Me in a sonication bath until the gel bands were totally shattered. One $\mathrm{mL}$ of water was added to the tube to partition the lipids into the chloroform phase, which was then transferred to a new tube and evaporated to dryness, followed by acid methanolysis as described above.

\section{Gas chromatography/mass spectrometry (GC/MS)}

Plant leaf samples were analyzed by using an Agilent 5975 mass-selective detector, coupled to an Agilent 6890 series gas chromatograph either equipped with a polar column (HP-INNOWax, $30 \mathrm{~m} \times 0.25 \mathrm{~mm}, 0.25 \mu \mathrm{m}$ film thickness) or a nonpolar column (HP-5MS, $30 \mathrm{~m} \times 0.25 \mathrm{~mm}, 0.25 \mu \mathrm{m}$ film 
thickness), and helium was used as carrier gas. For analysis of fatty acid methyl esters (FAMEs), the oven temperature was set at $80{ }^{\circ} \mathrm{C}$ for $1 \mathrm{~min}$, then increased to $230{ }^{\circ} \mathrm{C}$ at a rate of $10^{\circ} \mathrm{C} / \mathrm{min}$ and held for $10 \mathrm{~min}$.

To determine the position of double bonds in target compounds, DMDS derivatization was performed according to Dunkelblum et al. (1985). The DMDS adducts were analyzed by GC/MS on a nonpolar column (HP-5MS) using the following oven temperature program: $80^{\circ} \mathrm{C}$ for $2 \mathrm{~min}$, then increased at a rate of $15^{\circ} \mathrm{C} / \mathrm{min}$ to $140^{\circ} \mathrm{C}$, then increased at a rate of $5^{\circ} \mathrm{C} / \mathrm{min}$ to $260{ }^{\circ} \mathrm{C}$ and held for $3 \mathrm{~min}$.

\section{Statistical analysis}

Data were subjected to analysis of variance, and means were compared by unpaired $t$-test with two-tailed $P$ value by using the Prism software program (Prism 8 ). $P<0.05$ indicates a significant difference.

\section{Results}

\section{Fatty acid composition in N. tabacum and $N$. benthamiana leaves}

The GC/MS analysis showed that wild-type N. tabacum leaves contained $54 \pm 5 \%$ linolenic acid (18:3), $12 \pm 3 \%$ palmitic acid (16:0), $10 \pm 3 \%$ linoleic acid (18:2), $8 \pm 2 \%$ $(Z, Z, Z)-7,10,13$-hexadecatrienoic acid (16:3) and $2 \pm 1 \%$ stearic acid (18:0) (Table 1 and Fig. 2a). In addition, oleic acid (18:1), (Z,Z)-7,10-hexadecadienoic acid (16:2) and (Z)-13-hexadecenoic acid (16:1(13)) and arachidic acid (20:0) were found in the leaf (Table 1 and Fig. 2a). Wildtype $N$. benthamiana leaves showed a similar fatty acid composition as in $N$. tabacum, the majority of the total fatty acids were 18:3,18:2, 16:0 and 16:3, followed by

Table 1 Fatty acid compositions (weight \%) of total leaf lipids in the wild type and in T0 transgenic Nicotiana tabacum expressing acyl-ACP thioesterases and desaturases

\begin{tabular}{|c|c|c|c|c|c|c|c|c|c|c|c|c|c|}
\hline Genotype & $14: 0$ & 14:1(Z11) & 14:1(E11) & $16: 0$ & $16: 1(\mathrm{Z} 11)$ & $16: 1(13)$ & $16: 2$ & $16: 3$ & 18:0 & $18: 1$ & $18: 2$ & $18: 3$ & 20.0 \\
\hline Wild type & 0.1 & - & - & 12.2 & - & 2.4 & 1.1 & 7.6 & 1.7 & 1.0 & 10.8 & 54.2 & 0.3 \\
\hline \multicolumn{14}{|c|}{ CpaFatB2-Ave $\Delta 11$} \\
\hline \#001 & $0.2^{*}$ & 0 & 0 & $14.0^{*}$ & - & 1.6 & 0.9 & 10.5 & 1.5 & 1.0 & 7.6 & 54.0 & 0.2 \\
\hline \#002 & $0.2^{*}$ & 0 & 0 & $14.0^{*}$ & - & 2.1 & 0.8 & 11.0 & 1.3 & 0.7 & 7.1 & 53.6 & 0.2 \\
\hline \#003 & $0.2^{*}$ & 0 & 0 & $13.3^{*}$ & - & 2.4 & 1.0 & 10.0 & 1.0 & 0.9 & 10.4 & 53.5 & 0.2 \\
\hline \#004 & $0.2^{*}$ & 0 & 0 & $13.8^{*}$ & - & 2.0 & 0.9 & 12.0 & 1.2 & 0.8 & 8.0 & 52.3 & 0.2 \\
\hline$\# 005$ & $0.5^{*}$ & 0 & 0 & $16.4^{* *}$ & - & 1.7 & 0.8 & 10.9 & 1.2 & 0.7 & 7.7 & 49.9 & 0.1 \\
\hline \#006 & $0.8^{* *}$ & 0.1 & 0 & $28.7^{* * * *}$ & - & 0.8 & 0.4 & 2.1 & 1.7 & 0.4 & 8.2 & 48.1 & 0.4 \\
\hline \#007 & $1.7^{* *}$ & 0 & 0 & $14.1^{*}$ & - & 1.7 & 0.5 & 14.8 & 1.6 & 0.3 & 7.0 & 60.2 & 0.2 \\
\hline \#008 & $0.8^{* *}$ & 0 & 0 & 12.3 & - & 2.6 & 0.9 & 10.7 & 0.8 & 0.7 & 9.4 & 56.8 & 0.2 \\
\hline$\# 009$ & $1.9^{* *}$ & 0.1 & 0 & $32.7^{* * * *}$ & - & 1.4 & 0.5 & 3.7 & 1.2 & 0.5 & 12.0 & 43.5 & 0.2 \\
\hline \#010 & $3.1^{* * *}$ & 0.4 & 0.1 & $36.3^{* * * *}$ & - & 0.5 & 0.5 & 1.9 & 3.5 & 0.8 & 15.3 & 34.8 & 0.8 \\
\hline \#011 & $0.6^{* *}$ & 0 & 0 & 12.9 & - & 2.3 & 0.8 & 10.0 & 1.1 & 0.5 & 7.8 & 54.9 & 0.2 \\
\hline \#012 & $2.9^{* * *}$ & 0 & 0 & $15.7^{* *}$ & - & 1.5 & 1.1 & 3.9 & 2.6 & 1.1 & 9.8 & 44.8 & 0.4 \\
\hline \multicolumn{14}{|c|}{ CpaFatB2-СраE11 } \\
\hline \#001 & $5.5^{* * *}$ & - & 0.2 & $38.3^{* * * *}$ & - & 1.0 & 0.5 & 1.6 & 1.9 & 0.7 & 14.9 & 33.0 & 0.2 \\
\hline$\# 002$ & $3.6^{* * *}$ & - & 0.2 & $35.4^{* * * *}$ & - & 0.8 & 0.6 & 2.7 & 1.7 & 0.6 & 11.2 & 39.5 & 0.2 \\
\hline \#003 & $2.6^{* * *}$ & - & 0.1 & $36.0^{* * * *}$ & - & 0.8 & 0.4 & 2.2 & 2.9 & 0.6 & 14.4 & 37.3 & 0.4 \\
\hline$\# 004$ & $2.0^{* *}$ & - & 0.1 & $32.0^{* * * *}$ & - & 0.8 & 0.6 & 4.0 & 1.8 & 0.5 & 12.8 & 35.4 & 0.8 \\
\hline \multicolumn{14}{|c|}{ CpuFatB1-Atr $\Delta 11$} \\
\hline \#001 & $0.3^{*}$ & - & - & $20.1^{* * *}$ & 0.7 & 2.0 & 0.8 & 11.5 & 1.1 & 0.6 & 6.9 & 47.4 & 0.3 \\
\hline$\# 002$ & $0.4^{*}$ & - & - & $18.4^{* *}$ & 0.2 & 2.1 & 0.6 & 8.7 & 1.1 & 0.9 & 9.8 & 52.7 & 0.3 \\
\hline \#003 & $0.3^{*}$ & - & - & $19.8^{* *}$ & 0.9 & 1.7 & 1.0 & 11.7 & 0.8 & 0.5 & 7.1 & 49.6 & 0.5 \\
\hline \#004 & $0.2^{*}$ & - & - & $15.0^{* *}$ & 0.4 & 2.1 & 0.9 & 11.8 & 0.9 & 0.5 & 7.9 & 55.1 & 0.3 \\
\hline$\# 005$ & $0.3^{*}$ & - & - & $13.0^{* *}$ & 0.1 & 2.2 & 1.0 & 11.6 & 0.8 & 0.7 & 8.7 & 57.3 & 0.5 \\
\hline \#006 & $1.2^{* *}$ & - & - & $14.8^{* * *}$ & 0 & 2.2 & 1.0 & 7.6 & 1.6 & 1.0 & 8.3 & 51.4 & 0 \\
\hline \#007 & $1.6^{* *}$ & - & - & $30.0^{* * * *}$ & 0.5 & 3.6 & 1.3 & 6.4 & 1.4 & 1.2 & 12.4 & 44.4 & 0 \\
\hline
\end{tabular}

Values are the means of at least three biological replicates. Significance analysis was only applied to compare 14:0 and 16:0 between transformants and wild type by using unpaired t-test. *,**,*** indicate $P<0.05,0.01,0.001$, respectively 

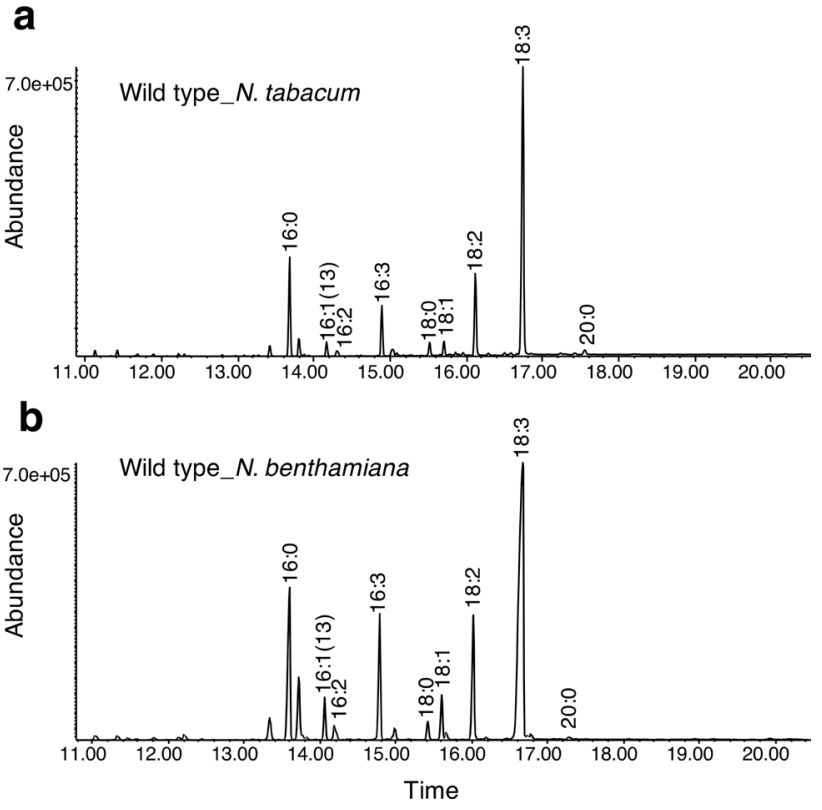

Fig. 2 Chromatograms of total fatty acids in wild-type a Nicotiana tabacum and $\mathbf{b} N$. benthamiana, in the form of corresponding methyl esters by GC/MS analysis. 16:0, palmitic acid; 16:1(13), (Z)13-hexadecenoic acid; 16:2, (Z,Z)-7,10-hexadecadienoic acid; 16:3, (Z,Z,Z)-7,10,13-hexadecatrienoic acid; 18:0, stearic acid; 18:1, oleic acid; 18:2, linoleic acid; 18:3, linolenic acid; 20:0, arachidic acid

16:1(13), 18:0 and 18:1, and besides that 16:2 and 20:0 were also detected (Table 2 and Fig. 2b).

A large variation in the production of 14:0, 16:0 and unsaturated pheromone precursors was observed in both $\mathrm{T} 0$ and T1 N. tabacum lines (Table 1 and Fig. 3). For production of $\mathrm{C}_{14}$ pheromone precursor in N. tabacum, CpaFatB2Ave $\Delta 11$ and CpaFatB2-CpaE11 transformants contained $14: 0$ and $16: 0$ from 0.2 to $5.5 \%$ and 12.3 to $38.3 \%$, respectively (Table 1), higher than the wild type which produced $0.1 \%$ of $14: 0$ and $12.2 \%$ of 16:0. CpaFatB2-Ave $\Delta 11$ transformants produced Z11-14:acid and a smaller amount of E11-14:acid (Fig. 4a), and CPaFatB2-CPaE11 transformants produced E11-14:acid (Fig. 4b). For production of $\mathrm{C}_{16}$ pheromone precursors in N. tabacum, CpuFatB1-Atr 11 transformants produced 0.2 to $1.6 \%$ of $14: 0$ and 13.0 to $30.0 \%$ of 16:0, higher than that from the wild-type plants (Table 1). Z11-16:acid was produced in the transformant lines up to $0.9 \%$ (Table 1 and Fig. 4c). Taking these transformant lines to a second generation did not improve the levels of pheromone precursor production (Fig. 3). Eight T1 plants from CpuFatB1-Atr $\Delta 11$ \#001 T0 parent produced 13.1 to $22.5 \%$ of 16:0 (Fig. 3a) and 0.1 to $1.0 \%$ of Z11-16:acid (Fig. 3b).

CpuFatB1-Atr $\Delta 11$ transformants of $N$. benthamiana also showed a large variation in T0 and T1 lines. T0 N. benthamiana transformants contained 15.0 to $31.6 \%$ of $16: 0$ (with the exception that \#027 plant produced $10.0 \%$ ), higher than the wild-type plants that produced an average of $14.8 \%$
(Table 2). These transformants produced Z11-16:acid (Fig. 4d), ranging from 0.1 to $4.8 \%$ (Table 2). Among the twenty-eight $\mathrm{T} 0$ transformants, six plants accumulated more than 2.0\% of Z11-16:acid (Table 2). The percentage of Z1116:acid varied significantly ( 0.3 to $4.2 \%$ ) among different leaves from same plant at the same stage, indicating presence of chimerism in the plant (Fig. S1). More than 150 $\mathrm{T} 1$ plants from five $\mathrm{T} 0$ parent plants (at least $30 \mathrm{~T} 1$ from each selected $\mathrm{T} 0$ ) were grown to the next generation, and the production of Z11-16:acid ranged from 0.1 to $10.1 \%$ (Fig. 5), thus in many cases reaching higher percentages as compared to the T0 plants. Besides this, the T1 plant \#02516 produced even higher proportion of Z11-16:acid in the mature leaves during plant flowering (Fig. 6). This line produced $17.6 \%$ Z11-16:acid, corresponding to $335 \mu \mathrm{g}$ per gram fresh leaf and equaling ca. $50 \mathrm{mg}$ Z11-16:acid in the entire plant. The highest 16:0 production recorded in $\mathrm{T} 1$ plants was $38.1 \%$ (Fig. 5), higher than the best T0 plant (Table 2). Five $\mathrm{T} 1$ plants from each line are propagated to next generation. Two T2 lines (\#00621, \#00830) still showed big variation in Z11-16:acid production (Fig. 5a-b). The other three T2 lines (\#00925, \#02516, \#02615) showed smaller variation (Fig. 5c-e), and in the \#02615 T2 line, we consider the Z1116:acid production stable (Fig. 5e).

\section{Fitness of transgenic N. tabacum and $N$. benthamiana}

Compared to the wild-type $N$. tabacum, the transgenic tobacco was growing much slower, and the leaves were less green when the CpaFatB2 was introduced. There were also small tissue lesions on the surface of leaves (data not shown). In addition, such deleterious effect on the leaves as well as delayed growth rate and chlorosis were more often observed in the plants that produced higher amounts of $\mathrm{Z} /$ E11-14:acid, and more than one-fifth of T1 plants of CpaFatB2-CpaE11 transformants did not survive during development (Fig. 3). However, no developmental problem was observed in CpuFatB1-Atr $\Delta 11$ transformed N. tabacum and $N$. benthamiana.

\section{Lipid fractions in transgenic $N$. benthamiana leaves}

In order to understand the distribution of pheromone precursors in transgenic $N$. benthamiana leaves, total lipids were separated by TLC into different molecular classes analysis (Fig. S2). The results showed that the wild-type leaves contain about $80 \%$ polar lipids (PL), $10 \%$ sterol esters (SE), $4 \%$ monoacylglycerols (MAG), 3\% triacylglycerols (TAG) and diacylglycerols (DAG) plus $1 \%$ free fatty acids (FFA) (Fig. 7a). Compared to the wild type, the amount of TAG and SE in the transgenic plants was significantly increased. 
Table 2 Fatty acid compositions (weight \%) of total leaf lipids in the wild type and in T0 transgenic Nicotiana benthamiana expressing acyl-ACP thioesterases and desaturases

\begin{tabular}{|c|c|c|c|c|c|c|c|c|c|c|c|}
\hline Genotype & $14: 0$ & $16: 0$ & $16: 1(\mathrm{Z} 11)$ & $16: 1(13)$ & $16: 2$ & $16: 3$ & $18: 0$ & $18: 1$ & $18: 2$ & $18: 3$ & 20.0 \\
\hline Wild type & 0.3 & 14.8 & - & 2.3 & 1.2 & 7.6 & 1.6 & 1.3 & 6.2 & 55.6 & 0.2 \\
\hline \multicolumn{12}{|c|}{ CpuFatB1_Atr $\Delta 11$} \\
\hline \#001 & $0.8^{* *}$ & $25.0^{* * *}$ & 1.0 & 1.7 & 1.0 & 2.1 & 3.3 & 1.1 & 4.9 & 36.1 & 0.4 \\
\hline \#002 & $0.7^{* *}$ & $18.0^{* * *}$ & 0 & 1.6 & 0.9 & 2.3 & 3.5 & 0.9 & 4.4 & 39.1 & 0.7 \\
\hline \#003 & 0.3 & $30.5^{* * *}$ & 0.6 & 0.7 & 0.8 & 1.8 & 3.5 & 1.6 & 9.6 & 38.6 & 0.4 \\
\hline \#004 & $0.9^{* *}$ & $26.1^{* * * *}$ & 0.8 & 0.7 & 0.7 & 1.6 & 3.7 & 2.8 & 12.8 & 34.5 & 0.7 \\
\hline \#005 & 0.2 & $19.8^{* *}$ & 0.1 & 0.2 & 1.0 & 0.5 & 10.1 & 13.9 & $\underline{13.0}$ & 27.2 & 1.7 \\
\hline \#006 & $0.4^{*}$ & $25.1^{* * *}$ & 3.2 & 0.8 & 1.2 & 1.1 & 2.9 & 0.2 & 4.8 & 40.1 & 0.5 \\
\hline \#007 & $0.6^{*}$ & $28.1^{* * *}$ & 1.8 & 2.0 & 0.7 & 1.7 & 2.5 & 0.4 & 3.8 & 39.6 & 0.3 \\
\hline \#008 & 0.3 & $24.3^{* * *}$ & 2.3 & 0.6 & 1.0 & 0.9 & 4.0 & 0.3 & 5.6 & 38.4 & 0.9 \\
\hline$\# 009$ & $0.5^{*}$ & $28.1^{* * *}$ & 4.8 & 1.5 & 0.8 & 1.7 & 2.5 & 2.1 & 5.0 & 44.4 & 0.3 \\
\hline$\# 010$ & $0^{*}$ & $27.0^{* * * *}$ & 1.1 & 0.7 & 1.3 & 1.0 & 7.4 & 1.1 & 8.5 & 42.7 & 0.8 \\
\hline \#011 & $0.1^{*}$ & $20.6^{* * *}$ & 0.1 & 1.4 & 1.0 & 1.4 & 6.7 & 1.2 & 7.1 & 50.3 & 0.2 \\
\hline \#012 & $0.4^{*}$ & $28.6^{* * * *}$ & 2.2 & 0.9 & 0.7 & 2.0 & 1.9 & 0.3 & 3.5 & 55.9 & 0.3 \\
\hline \#013 & $0.4^{*}$ & $20.1^{* *}$ & 0.5 & 1.5 & 0.9 & 1.8 & 3.8 & 2.2 & 9.4 & 48.6 & 0.9 \\
\hline \#014 & 0.3 & $17.9^{* * *}$ & 0.1 & 1.3 & 0.5 & 2.1 & 3.3 & 1.2 & 8.5 & 56.1 & 0.4 \\
\hline \#015 & $0.5^{*}$ & $17.8^{* * *}$ & 0 & 1.4 & 0.6 & 2.4 & 2.6 & 0.8 & 5.7 & 55.0 & 0.5 \\
\hline \#016 & $0.6^{*}$ & $31.6^{* * *}$ & 0 & 1.2 & 1.6 & 0.9 & 4.3 & 0.8 & 7.2 & 44.2 & 0.6 \\
\hline \#017 & $0.6^{*}$ & $28.8^{* * * *}$ & 1.8 & 1.6 & 0.9 & 2.7 & 1.5 & 0.7 & 5.7 & 45.3 & 0.3 \\
\hline \#018 & $0.4^{*}$ & $23.0^{* *}$ & 1.9 & 2.0 & 0.7 & 4.1 & 1.1 & 1.0 & 6.6 & 51.7 & 0.1 \\
\hline \#019 & $0.5^{*}$ & $29.1^{* * *}$ & 1.8 & 2.0 & 1.3 & 3.0 & 2.5 & 2.1 & 8.2 & 40.5 & 0 \\
\hline \#020 & $0.4^{*}$ & $27.5^{* * *}$ & 1.9 & 0.6 & 0.8 & 1.1 & 3.7 & 0.5 & 8.0 & 39.6 & 0.5 \\
\hline \#021 & $0.4^{*}$ & $24.8^{* * * *}$ & 1.7 & 1.5 & 0.6 & 2.6 & 2.1 & 0.3 & 3.1 & 49.1 & 0.4 \\
\hline \#022 & $0.6^{*}$ & $29.0^{* * * *}$ & 2.3 & 1.1 & 0.5 & 1.3 & 2.9 & 0.9 & 4.0 & 42.0 & 0.5 \\
\hline \#023 & $0.4^{*}$ & $17.7^{*}$ & 0.2 & 1.5 & 0.5 & 1.4 & 4.8 & 0.2 & 6.9 & 43.0 & 0.6 \\
\hline \#024 & 0.3 & $26.1^{* * * *}$ & 1.9 & 1.4 & 0.7 & 4.8 & 1.7 & 0.2 & 6.7 & 46.7 & 0.5 \\
\hline \#025 & 0.3 & $24.4^{* * * *}$ & 1.7 & 1.8 & 0.8 & 4.7 & 1.6 & 1.1 & 6.7 & 45.9 & 0.5 \\
\hline \#026 & $0.5^{*}$ & $28.0^{* * * *}$ & 4.4 & 1.5 & 0.2 & 5.2 & 1.6 & 1.3 & 4.4 & 49.1 & 0.5 \\
\hline \#027 & 0.2 & $10.0^{* * *}$ & 0 & 0.7 & 0.3 & 0.7 & 2.9 & 0.8 & 4.4 & 26.0 & 1.8 \\
\hline \#028 & $0.5^{*}$ & $29.6^{* * * *}$ & 1.8 & 1.5 & 0.9 & 3.9 & 2.4 & 2.3 & 10.6 & 39.3 & 1.1 \\
\hline
\end{tabular}

Values are the means of at least three biological replicates. Significance analysis was only applied to compare 14:0 and 16:0 between transformants and wild type by using unpaired $t$-test. *, **,*** indicate $P<0.05,0.01,0.001$, respectively. The unusually high percentage of fatty acids are indicated by underline
In wild-type leaves, nearly $80 \%$ of $16: 0$ was present in PL, and small amount of 16:0 was found in SE, TAG, MAG and DAG, whereas the transformed leaves showed a significant enrichment of 16:0 in the TAG and SE, at about 20-40\%. A small fraction of 16:0 was present in the MAG, DAG and FFA, at a similar level as in the wild type. The pheromone precursor Z11-16:acid shows a similar distribution to 16:0 (Fig. 7b).

\section{Discussion}

The successful production of several insect sex pheromone precursors in $N$. tabacum and $N$. benthamiana by stable transformation was demonstrated in this study. All of the transformed plastid thioesterases and fatty acyl desaturases were functionally active in producing pheromone precursor in both Nicotiana species. This is the first report of Z/E1114:acid production in a plant by stable transformation and levels of up to $17.6 \% \mathrm{Z11}-16$ :acid of the total fatty acids was achieved. The Z11-16:acid production in $N$. benthamiana was better than in $N$. tabacum (Tables 1 and 2). The average value of Z11-16:acid production in T0 N. tabacum was $0.2 \%$ (Table 1), whereas in T0 N. benthamiana, it was $1.8 \%$ (Table 2). The best $N$. benthamiana transgenic line \#025 produced as high as 13.6\% of Z11-16:acid of the total fatty acids in T2 plants (Fig. 5), which is much higher than the production reported by Nešnerová et al. (2004), who claimed that $6 \%$ of Z11-16:acid of total fatty acids was produced in their transgenic $N$. tabacum NtD15B line. The quantity of Z11-16:acid in N. benthamiana was calculated as $335 \mu \mathrm{g}$ per gram fresh leaf, compared to $32 \mu \mathrm{g}$ per gram of $N$. tabacum fresh leaf in Nešnerová et al. 2004. The results suggest that $N$. benthamiana has potential to be more efficient than $N$. 
a

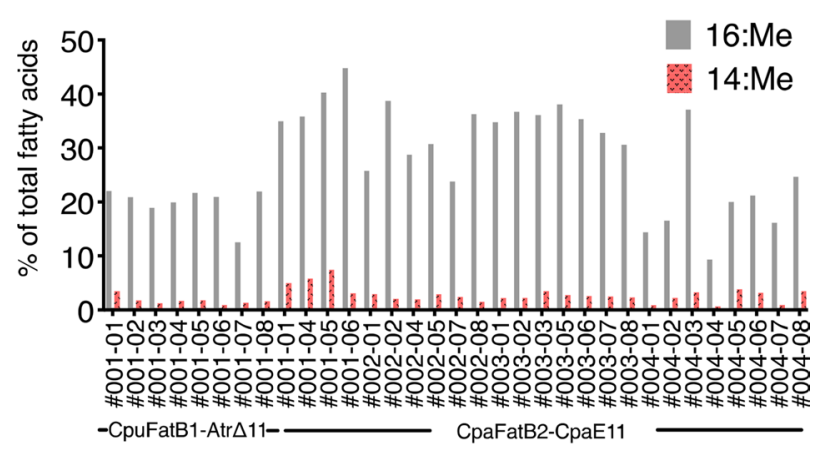

b

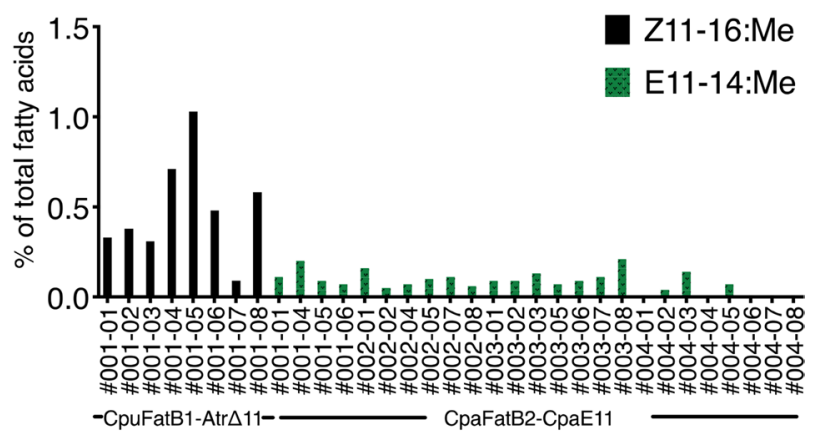

T1 lines

Fig. 3 Percentage of a palmitic acid (16:0) and myristic acid (14:0), and $\mathbf{b}$ pheromone precursors Z11-16:acid and E11-14:acid of total fatty acids in T1 leaves of Nicotiana tabacum. Fatty acids were analyzed in form of corresponding methyl esters. 16:Me, Methyl palmitate; 14:Me, Methyl myristate; Z11-16:Me, (Z)-11-hexadecenoic acid methyl ester; E11-14:Me, (E)-11-tetradecenoic acid methyl ester. Eight T1 plants for each line were numbered and cultivated from the beginning, but some of them died during the growing process, that is the reason for absence of some CpaFatB2-CpaE11 T1 plants

tabacum as a plant factory for Z11-16:acid production. In the study of Ding et al. (2014), $381 \mu \mathrm{g}$ per gram fresh leaf of Z11-16:acid was produced in $N$. benthamiana by transient expression, which is a massive overexpression of exogenous genes over a few days that ignores the health of the plant. Here, the production of $335 \mu \mathrm{g}$ per gram leaf of Z11-16:acid by stable transformation shows the ability of vegetative material to function with the expression of CpuFatBI and Atr $\Delta 11$ and yield compounds over development, providing the potential for further commercial production.

Interestingly, although at low levels, we detected the elongation product (Z)-13-octadecenoic acid (Z13-18:acid) in both transformed $N$. benthamiana and $N$. tabacum lines when the Z11-16:acid was produced. This indicates that the novel fatty acids are accepted by an endogenous fatty acyl elongase in both species. Additionally, it is interesting that both wild-type $N$. tabacum and $N$. benthamiana produce more than $2 \%$ monounsaturated (Z)-13-hexadecenoic acid (Z13-16:acid) in their fatty acid profiles. Z13-16:acid is a pheromone precursor of the moth Herpetogramma submarginale (Yan et al. 2015b), which uses (Z)-13-hexadecenyl acetate (Z13-16:OAc) as its major sex pheromone component.

Moreover, it is observed that in transgenic $N$. benthamiana T1 plant \#025-16, the amount of Z11-16:acid increased from $10.1 \%$ of total fatty acids in 6 -week-old plants to $17.6 \%$ in 3-month-old flowering plants (Fig. 6). This may be due to some of the fatty acids being re-allocated from polar lipids to neutral lipids during the plant development. The fatty acids in the leaves reach a maximum at early flowering (Chu and Tso 1968; Leech et al. 1973), which provides an improvement of substrates to desaturase during leaf oil accumulation. The overexpression of acyl-ACP thioesterases has previously been reported to modify oil profile in transgenic plants (Mandal et al. 2000; Salas et al. 2002; Voelker et al. 1996). Overexpression of Arabidopsis thaliana thioesterases in transgenic $N$. benthamiana leaf was confirmed to increase the TAG as well (EI-Tahchy et al. 2017). Our results of lipid distribution in $N$. benthamiana leaves also indicate that the thioesterase gene CpuFatBl elevated the TAG amount, leading to an increase in pheromone precursor levels (Fig. 7). Medium-chain fatty acids (MCFA) produced in leaves result in unbalanced membrane lipid profiles and undesirable chlorosis and cell death (Reynolds et al. 2017), which we think might be the reason for low productivity of pheromone precursors and insignificant increase of 14:0. Also, the deleterious effect on the CpaFatB2-CpaE11 N. tabacum transformants is likely caused by the E11-14:acid product rather than 14:0, because no deleterious effect was observed in CpuFatB1-AtrDl1 transformed Nicotiana spp., which also produced higher 14:0 than the wild-type plants. Reynolds et al. (2017) demonstrated that overexpression of the KENNEDY pathway genes can push the MCFA to the TAG pool to increase the MCFA production in leaf oils without disturbing membrane homoeostasis and cell death. Therefore, to improve TAG accumulation could be a means to increase the production of pheromone precursor by sequestering products into TAG instead of ending up in membranes with a negative influence on plant function and health.

Typically TAG accounts for less than $1.5 \%$ of the total leaf fatty acids and takes up less than $3 \%$ of de novo synthesized fatty acids (Fan et al. 2013a; Yang and Ohlrogge 
Fig. 4 Total lipids GC chromatograms of a CpaFatB2Ave11, b CpaFatB2-CpaE11, c CpuFatB1-Atr $\Delta 11$ transformants from Nicotiana tabacum and d CpuFatB1Atr $\Delta 11$ transformants from $N$. benthamiana. GC/MS analysis of fatty acids in the form of corresponding methyl esters. The target pheromone precursors specifically produced by transformants were indicated in italic and bold. Z11-14:Me, (Z)-11-tetradecenoic acid methyl ester; E11-14:Me, (E)-11-tetradecenoic acid methyl ester; Z11-16:Me, (Z)11-hexadecenoic acid methyl ester; 14:0, myristic acid; 16:0, palmitic acid; 16:1(13), (Z)-

13-hexadecenoic acid; 16:2, (Z,Z)-7,10-hexadecanoic acid; 16:3, (Z,Z,Z)-7,10,13-hexadecanoic acid; 18:0, stearic acid; $18: 1$, oleic acid; $18: 2$, linoleic acid; 18:3, linolenic acid; 20:0, arachidic acid
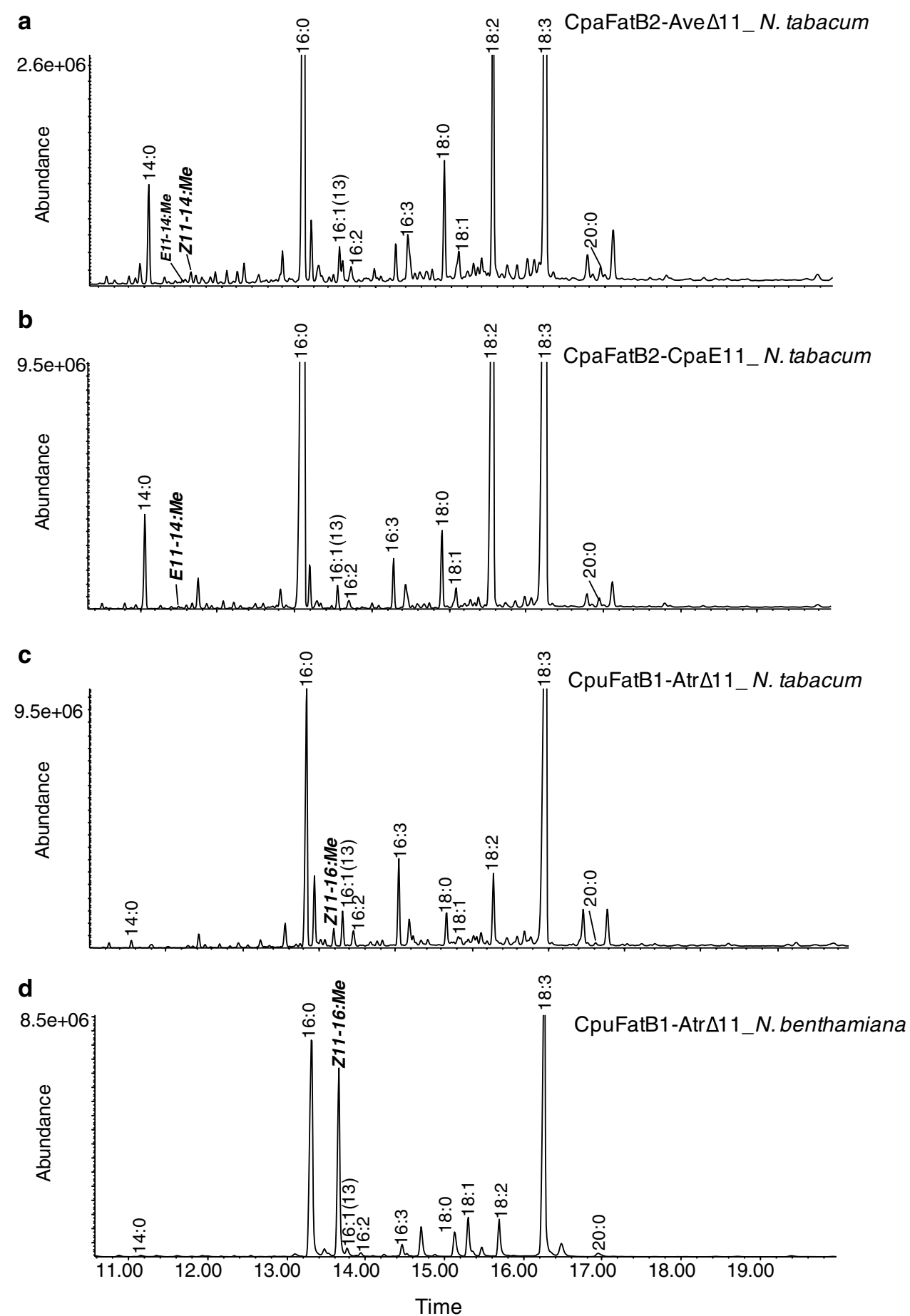

2009). However, benefitting from the development of biotechnology and utilizing bioengineering approaches the levels of TAG in the leaves may increase up to 30-33\% TAG (Vanhercke et al. 2017; Cernac and Benning 2004; Eastmond 2006; Kelly et al. 2011; Santos-Mendoza et al. 2008;
Hu et al. 2017; Nguyen et al. 2015; Pidkowich et al. 2007). This may be implemented as existing possibilities in order to optimize the plant factory in future studies. Furthermore, increasing the exogenous gene activities by modification of promoters and enhancer (Kay et al. 1987; Minetoki et al. 
a
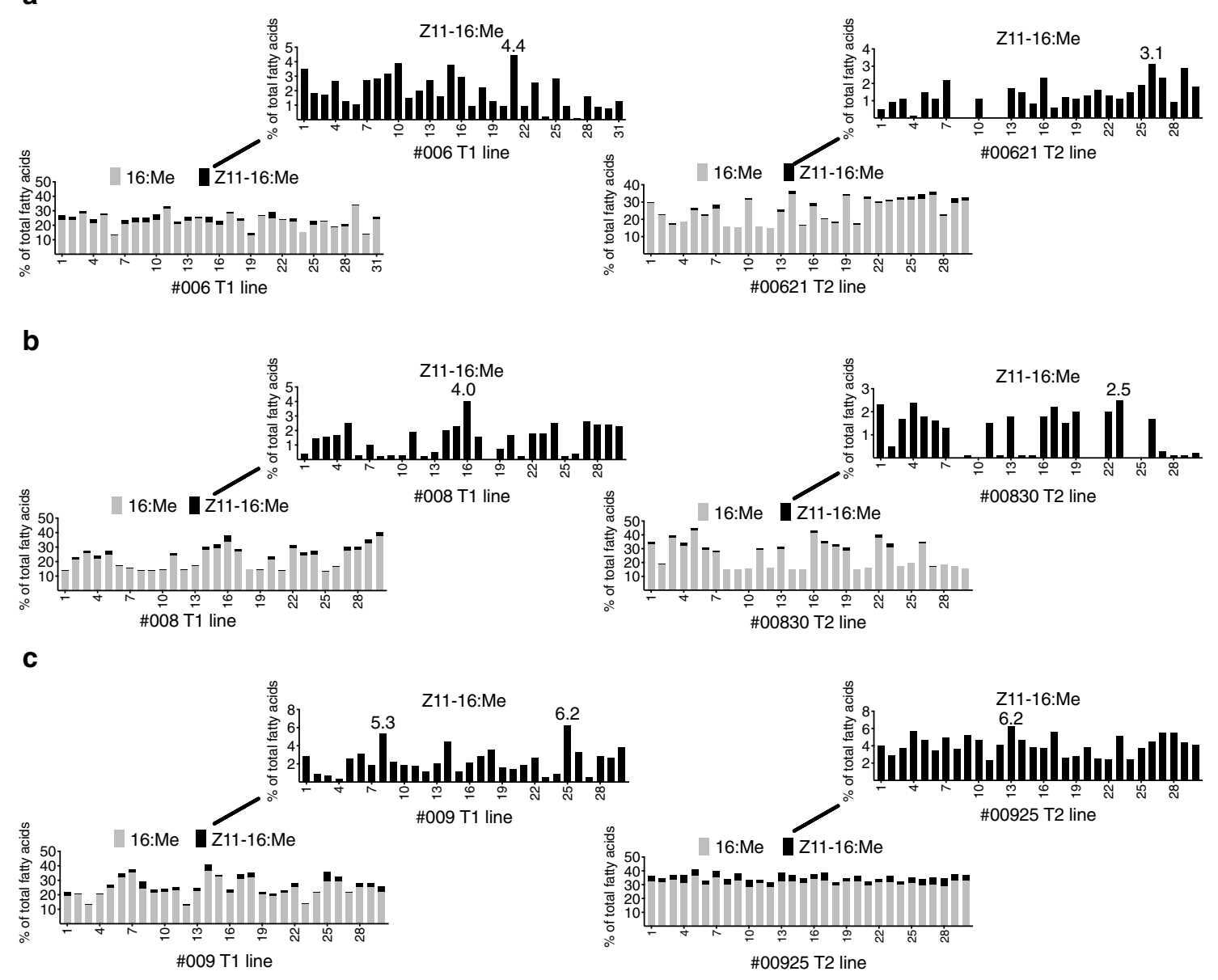

d

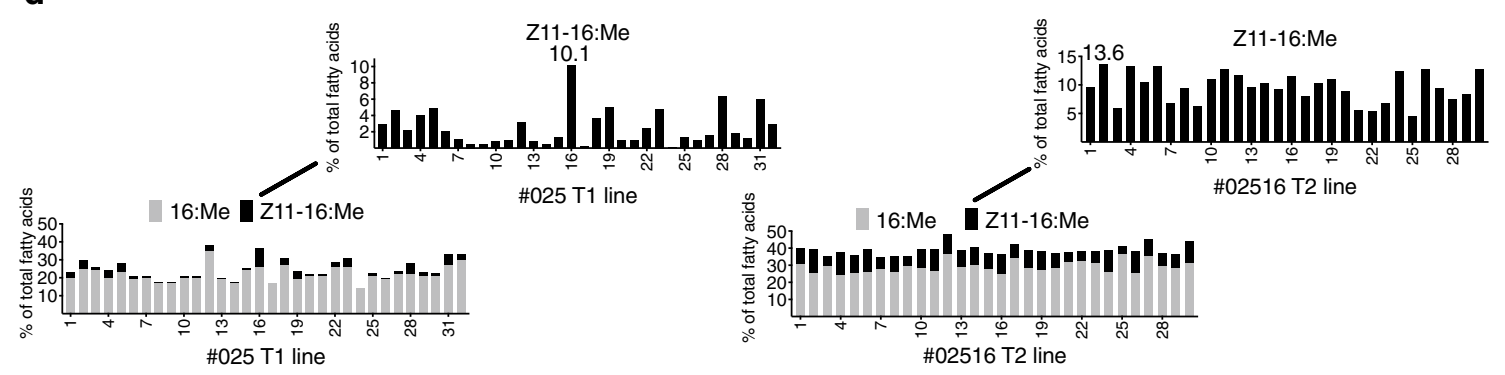

e

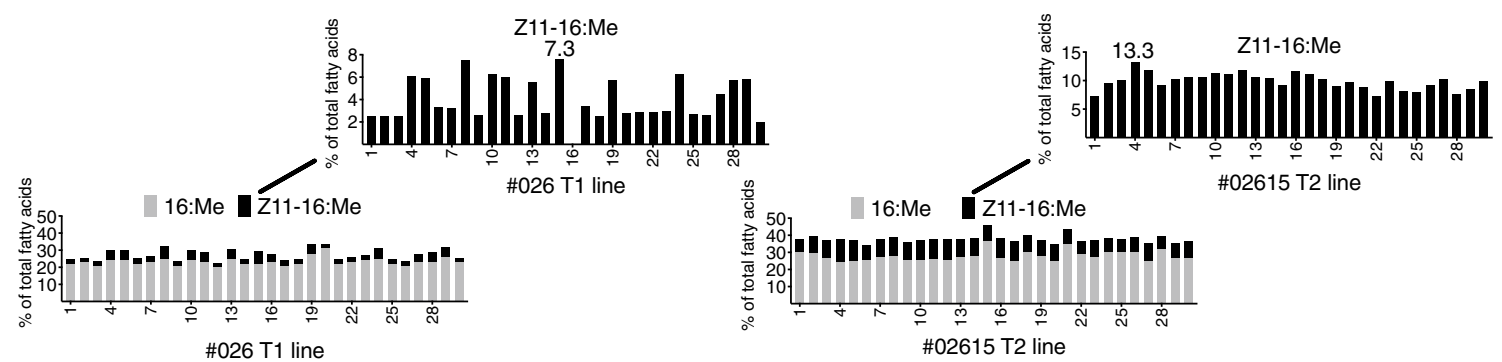

Fig. 5 Percentage of palmitic acid (16:0) and (Z)-11-hexadecenoic acid (Z11-16:acid) of total fatty acids in the form of corresponding methyl esters in T1 and T2 leaves of Nicotiana benthamiana from a \#006 and \#00621 line; b \#008 and \#00830 line; c \#009 and \#00925 line; d \#025 and \#02516 line; e \#026 and \#02615 line Fatty acids were analyzed in form of corresponding methyl esters. 16:Me, Methyl palmitate; Z11-16:Me, (Z)-11-hexadecenoic acid methyl ester. The histogram at the top right corner for each line is the zoomed in $y$-axis for Z11-16:acid. Fatty acids were analyzed in form of corresponding methyl esters 


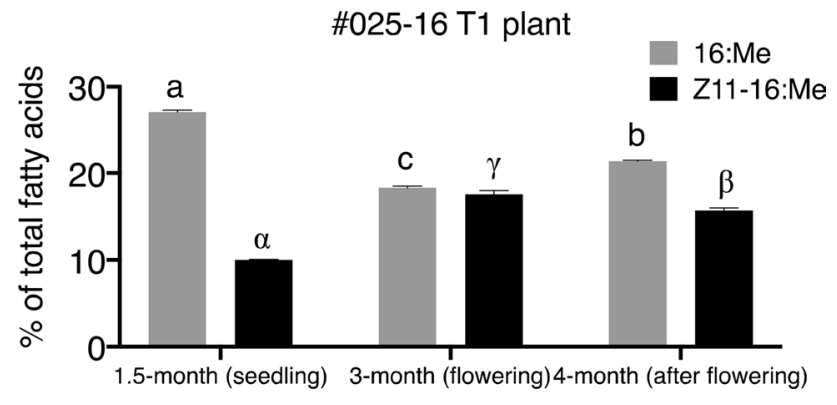

Fig. 6 Percentage of palmitic acid (16:0) and (Z)-11-hexadecenoic acid (Z11-16:acid) of total fatty acids in T1 plant \#025-16 leaves during different development stages of plant. Fatty acids were analyzed in form of corresponding methyl esters. 16:Me, Methyl palmitate; Z11-16:Me, (Z)-11-hexadecenoic acid methyl ester. Values are the means \pm standard error of the mean (SEM) from three replicates. The different letters above the standard error bar indicate a significant difference between the means. The P value less than 0.05 is statistically significant

1998), transformation of multiple transgene copies (Carrier et al. 1998; Mansur et al. 2005; Nguyen et al. 2015; Schultz et al. 1987; Fath et al. 2011) and transformation of virus silencing suppressor genes (Naim et al. 2016) might also contribute to higher quantity of pheromone precursor in plant factories.

In conclusion, in the present study we established a novel approach for stable production of moth sex pheromone precursors. Nicotiana spp. were genetically modified for production of pheromone precursors via integration of genes using Agrobacterium-mediated leaf-disc transformation. This is the first report on an extended production of insect pheromone precursors over generations in plants. Our best line of $N$. benthamiana produced $335 \mu \mathrm{g}$ of the target compound per gram of fresh leaf, demonstrating it a good platform species for production of $\mathrm{C}_{16}$ pheromone precursors, which can be simply converted into pheromones by a semi-synthetic approach. Considering that the production of $N$. benthamiana green biomass is as high as 100-300 tons per hectare (Sheen, 1983; Werner et al. 2011), a worthwhile amount of pheromone precursors may be produced by cultivating our most productive $N$. benthamiana line under field conditions. Also, our study is a step forward toward our long-term vision of producing moth pheromones in stably transformed plants that can be used for direct emission of the pheromones for attraction or mating disruption. a

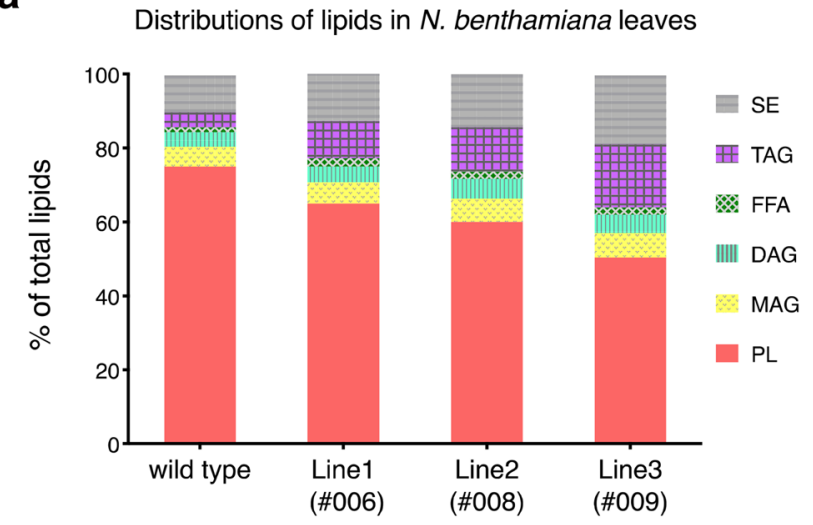

b

Distributions of 16:0 and Z11-16:acid in $N$. benthamiana leaves

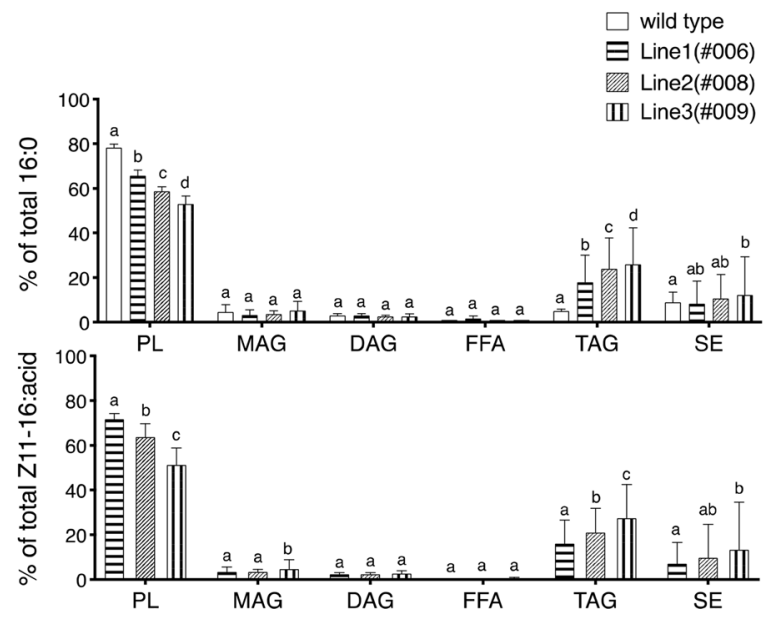

Fig. 7 Leaf fatty acid distribution in Nicotiana benthamiana CpuFatB1-Atr $\Delta 11$ transformants and wild-type plant. a Comparison of total lipids distributions between transformed lines and wild type. b Comparison of 16:0 and Z11-16:acid distributions between transformed lines and wild type. Fatty acids were analyzed in the form of methyl esters. SE, sterol esters; FFA, free fatty acids; TAG, triacylglycerols; DAG, diacylglycerols; MAG, monoacylglycerols; PL, polar lipids. 16:0, palmitic acid; Z11-16:acid, (Z)-11-hexadecenoic acid. Values are the means \pm standard error of the mean (SEM) from three replicates. The different letters above the standard error bar indicate a significant difference between the means. The $P$ value less than 0.05 is statistically significant

\section{Author contributions statement}

YHX, BJD, HLW, CJS, PH and CL conceived and designed the study. YHX and BJD carried out vector design and sequencing; YHX performed leaf-disc transformation, 
plant cultivation and all the sample analysis; YHX drafted the manuscript, and all authors reviewed and edited the manuscript.

Acknowledgement Open access funding provided by Lund University. This work was supported by grants from the Carl Trygger Foundation for Scientific Research, Swedish Foundation for Strategic Research (Oil Crops for the Future), and FORMAS to Christer Löfstedt. The Chinese Scholarship Council supported Yihan Xia's PhD scholarship. We would like to thank Prof. Edgar Cahoon for providing the CpuFatB1 gene plasmid and Erling Jirle for excellent technical support.

\section{Compliance with ethical standards}

Conflict of interest The authors declare that there is no conflict of interest for the current study.

Open Access This article is licensed under a Creative Commons Attribution 4.0 International License, which permits use, sharing, adaptation, distribution and reproduction in any medium or format, as long as you give appropriate credit to the original author(s) and the source, provide a link to the Creative Commons licence, and indicate if changes were made. The images or other third party material in this article are included in the article's Creative Commons licence, unless indicated otherwise in a credit line to the material. If material is not included in the article's Creative Commons licence and your intended use is not permitted by statutory regulation or exceeds the permitted use, you will need to obtain permission directly from the copyright holder. To view a copy of this licence, visit http://creativecommons.org/licenses/by/4.0/.

\section{References}

Ando T, Koshihara T, Yamada H, Vu MH, Takahashi N, Tamaki Y (1979) Electroantennogram activities of sex pheromone analogues and their synergistic effect on field attraction in the diamondback moth. Appl Entomol Zool 14:362-364

Aslan S, Sun C, Leonova S, Dutta P, Dörmann P, Domergue F, Hofvander P (2014) Wax esters of different compositions produced via engineering of leaf chloroplast metabolism in Nicotiana benthamiana. Metab Eng 25:103-112

Atanassov II, Etchells J, Turner SR (2009) A simple, flexible and efficient PCR-fusion/Gateway cloning procedure for gene fusion, site-directed mutagenesis, short sequence insertion and domain deletions and swaps. Plant Methods 5:14

Bao X, Focke M, Pollard M, Ohlrogge J (2000) Understanding in vivo carbon precursor supply for fatty acid synthesis in leaf tissue. Plant J 22:39-50

Beale MH, Birkett MA, Bruce TJ, Chamberlain K, Field LM, Huttly AK, Martin JL, Parker R, Philips AL, Pickett JA, Prosser LM, Shewry PR, Smart LE, Wadhams LJ, Woodcock CM, Zhang YH (2006) Aphid alarm pheromone produced by transgenic plants affects aphid and parasitoid behavior. Proc Nat Acad Sci 103:10509-10513

Boehm R (2007) Bioproduction of therapeutic proteins in the 21st century and the role of plants and plant cells as production platforms. Ann N Y Acad Sci 1102:121-134

Brittain C, Potts SG (2011) The potential impacts of insecticides on the life-history traits of bees and the consequences for pollination. Basic Appl Ecol 12:321-331

Bull D (1982) A growing problem: pesticides and the Third World poor. Oxfam
Carrier T, Jones KL, Keasling JD (1998) mRNA stability and plasmid copy number effects on gene expression from an inducible promoter system. Biotechnol Bioeng 59:666-672

Cernac A, Benning C (2004) WRINKLED1 encodes an AP2/EREB domain protein involved in the control of storage compound biosynthesis in Arabidopsis. Plant J 40:575-585

Chu H, Tso TC (1968) Fatty acid composition in tobacco I. Green tobacco plants. Plant Physiol 43:428-433

Clemente T (2006) Nicotiana (Nicotiana tabacum, Nicotiana benthamiana). In: Wang K (ed) Agrobacterium protocols. Humana Press, Totowa, pp 143-154

Dehesh K, Edwards P, Hayes T, Cranmer AM, Fillatti J (1996) Two novel thioesterases are key determinants of the bimodal distribution of acyl chain length of Cuphea palustris seed oil. Plant Physiol 110:203-210

Ding BJ, Hofvander P, Wang HL, Durrett TP, Stymne S, Löfstedt C (2014) A plant factory for moth pheromone production. Nat Commun 5:3353

Dunkelblum E, Tan SH, Silk PJ (1985) Double-bond location in monounsaturated fatty acids by dimethyl disulfide derivatization and mass spectrometry: application to analysis of fatty acids in pheromone glands of four Lepidoptera. J Chem Ecol 11:265-277

Eastmond PJ (2006) SUGAR-DEPENDENT1 encodes a patatin domain triacylglycerol lipase that initiates storage oil breakdown in germinating Arabidopsis seeds. Plant Cell 18:665-675

El Tahchy A, Reynolds KB, Petrie JR, Singh SP, Vanhercke T (2017) Thioesterase overexpression in Nicotiana benthamiana leaf increases the fatty acid flux into triacylgycerol. FEBS Lett 591:448-456

Fan J, Yan C, Xu C (2013) Phospholipid: diacylglycerol acyltransferase-mediated triacylglycerol biosynthesis is crucial for protection against fatty acid-induced cell death in growing tissues of Arabidopsis. Plant J 76:930-942

Fath S, Bauer AP, Liss M, Spriestersbach A, Maertens B, Hahn P, Ludwig C, Schäfer F, Graf M, Wagner R (2011) Multiparameter RNA and codon optimization: a standardized tool to assess and enhance autologous mammalian gene expression. PLoS ONE 6:e17596

Gatz C, Frohberg C, Wendenburg R (1992) Stringent repression and homogeneous de-repression by tetracycline of a modified CaMV 35S promoter in intact transgenic tobacco plants. Plant J 2:397-404

Heinemann FS, Ozols J (2003) Stearoyl-CoA desaturase, a shortlived protein of endoplasmic reticulum with multiple control mechanisms. Prostag Leukotr Ess 68:123-133

Horsch RB, Rogers SG, Fraley RT (1985) Transgenic plants. Cold Spring Harb Symp Quant Biol 50:433-437

Hu Z, Wu Q, Dalal J, Vasani N, Lopez HO, Sederoff HW, Qu R (2017) Accumulation of medium-chain, saturated fatty acyl moieties in seed oils of transgenic Camelina sativa. PLoS ONE 12:e0172296

Karg SR, Kallio PT (2009) The production of biopharmaceuticals in plant systems. Biotechnol Adv 27:879-894

Kay R, Chan AMY, Daly M, McPherson J (1987) Duplication of CaMV 35S promoter sequences creates a strong enhancer for plant genes. Science 236:1299-1302

Kehat M, Dunkelblum E (1990) Behavioral responses of male Heliothis armigera (Lepidoptera: Noctuidae) moths in a flight tunnel to combinations of components identified from female sex pheromone glands. J Insect Behav 3:75-83

Kelly AA, Quettier AL, Shaw E, Eastmond PJ (2011) Seed storage oil mobilization is important but not essential for germination or seedling establishment in Arabidopsis. Plant Physiol 157:866-875

Kim HJ, Silva JE, Vu HS, Mockaitis K, Nam JW, Cahoon EB (2015) Toward production of jet fuel functionality in oilseeds: identification of FatB acyl-acyl carrier protein thioesterases and evaluation 
of combinatorial expression strategies in Camelina seeds. J Exp Bot 66:4251-4265

Leech RM, Rumsby MG, Thomson WW (1973) Plastid differentiation, acyl lipid, and fatty acid changes in developing green maize leaves. Plant Physiol 52:240-245

Li-Beisson Y, Shorrosh B, Beisson F, Andersson MX, Arondel V, Bates PD, Baud S, Bird D, Debono A, Durrett TP, Franke RB, Graham IA, Katayama K, Kelly AA, Larson T, Markham JE, Miquel M, Molina I, Nishida I, Rowland O, Samuels L, Schmid KM, Wada H, Welti R, Xu C, Zallot R, Ohlrogge J (2013) Acyl-lipid metabolism. Arabidopsis Book 11:e0161

Liénard D, Sourrouille C, Gomord V, Faye L (2007) Pharming and transgenic plants. Biotechnol Annu Rev 13:115-147

Liu W, Jiao H, Murray NC, O'Connor M, Roelofs WL (2002) Gene characterized for membrane desaturase that produces $(E)-11$ isomers of mono-and diunsaturated fatty acids. Proc Nat Acad Sci 99:620-624

Liu W, Rooney AP, Xue B, Roelofs WL (2004) Desaturases from the spotted fireworm moth (Choristoneura parallela) shed light on the evolutionary origins of novel moth sex pheromone desaturases. Gene 342:303-311

Lotan T, Ohto M, Yee KM, West MA, Lo R, Kwong RW, Yamagishi K, Fischer RL, Harada GRBJJ (1998) Arabidopsis LEAFY COTYLEDON1 is sufficient to induce embryo development in vegetative cells. Cell 93:1195-1205

Löfstedt C, Wahlberg N, Millar JM (2016) Evolutionary patterns of pheromone diversity in Lepidoptera. In: Allison JD, Cardé RT (eds) Pheromone communication in moths: evolution, behavior and application. University of California Press, California, pp 43-82

Lynch RE, Klun JA, Leonhardt BA, Schwarz M, Garner JW (1984) Female sex pheromone of the lesser cornstalk borer, Elasmopalpus lignosellus (Lepidoptera: Pyralidae). Environ Entomol 13:121-126

Ma JK, Chikwamba R, Sparrow P, Fischer R, Mahoney R, Twyman RM (2005) Plant-derived pharmaceuticals-the road forward. Trends Plant Sci 10:580-585

Mandal MNA, Santha IM, Lodha ML, Mehta SL (2000) Cloning of acyl-acyl carrier protein (ACP) thioesterase gene from Brassica juncea. Biochem Soc Trans 28:967-969

Mansur M, Cabello C, Hernández L, País J, Varas L, Valdés J, Terrero Y, Hidalgo A, Plana L, Besada V, García L, Lamazares E, Castellanos L, Martínez E (2005) Multiple gene copy number enhances insulin precursor secretion in the yeast Pichia pastoris. Biotechnol Lett 27:339-345

Mett V, Farrance CE, Green BJ, Yusibov V (2008) Plants as biofactories. Biologicals 36:354-358

Minetoki T, Kumagai C, Gomi K, Kitamoto K, Takahashi K (1998) Improvement of promoter activity by the introduction of multiple copies of the conserved region III sequence, involved in the efficient expression of Aspergillus oryzae amylase-encoding genes. Appl Microbiol Biotechnol 50:459-467

Mori K (2007) The synthesis of insect pheromones. In: Ap-Simon J, Goldsmith DJ (eds) Total Synthesis of Natural Products. Wiley, Hoboken, pp 1979-1989

Mori K (2010) Chemical synthesis of hormones, pheromones and other bioregulators. Wiley, Hoboken

Murashige T, Skoog F (1962) A revised medium for rapid growth and bioassays with Tobacco tissue cultures. Physiol Plant 15:473-497

Naim F, Nakasugi K, Crowhurst RN, Hilario E, Zwart AB, Hellens RP, Wood CC (2012) Advanced engineering of lipid metabolism in Nicotiana benthamiana using a draft genome and the V2 viral silencing-suppressor protein. PLoS ONE 7:e52717

Naim F, Shrestha P, Singh S, Waterhouse PM, Wood CC (2016) Stable expression of silencing-suppressor protein enhances the performance and longevity of an engineered metabolic pathway. Plant Biotechnol J 14:1418-1426

Nešněrová P, Šebek P, Macek T, Svatoš A (2004) First semi-synthetic preparation of sex pheromones. Green Chem 6:305-307

Nguyen HT, Park H, Koster KL, Cahoon RE, Nguyen HT, Shanklin J, Clementa TE, Cahoon EB (2015) Redirection of metabolic flux for high levels of omega-7 monounsaturated fatty acid accumulation in Camelina seeds. Plant Biotechnol J 13:38-50

Nieukerken EV, Kaila L, Kitching IJ, Kristensen NP, Lees DC, Minet J, Mitter C, Mutanen M, Regier JC, Simonsen TJ, Wahlberg N, Yen SH, Zahiri R, Adamski D, Baixeras J, Bartsch D, Bengtsson BÅ, Brown JW, Bucheli SR, Davis DR, Prins JD, Prins WD, Epstein ME, Gentili-Poole P, Gielis C, Hättenschwiler P, Hausmann A, Holloway JD, Kallies A, Karsholt O, Kawahara AY, Koster SJC, Kozlov MV, Lafontaine JD, Lamas G, Landry J, Lee S, Nuss M, Park K, Penz C, Rota J, Schintlmeister A, Schmidt BC, Sohn JC, Solis MA, Tarmann GM, Warren AD, Weller S, Yakovlev RV, Zolotuhin V, Zwick A (2011) Order Lepidoptera Linnaeus, 1758. Zootaxa 3148:212-221

Pidkowich MS, Nguyen HT, Heilmann I, Ischebeck T, Shanklin J (2007) Modulating seed beta-ketoacylacyl carrier protein synthase II level converts the composition of a temperate seed oil to that of a palmlike tropical oil. Proc Nat Acad Sci 104:4742-4747

Reddy GVP, Guerrero A (2000) Pheromone-based integrated pest management to control the diamondback moth Plutella xylostella in cabbage fields. Pest Manag Sci 56:882-888

Reynolds KB, Taylor MC, Cullerne DP, Blanchard CL, Wood CC, Singh SP, Petrie JR (2017) A reconfigured Kennedy pathway which promotes efficient accumulation of medium-chain fatty acids in leaf oils. Plant Biotechnol J 15:1397-1408

Reynolds KB, Taylor MC, Zhou XR, Vanhercke T, Wood CC, Blanchard CL, Petrie JR (2015) Metabolic engineering of mediumchain fatty acid biosynthesis in Nicotiana benthamiana plant leaf lipids. Front Plant Sci 6:164

Rothschild GHL, Nesbitt BF, Beevor PS, Cork A, Hall DR, Vickers RA (1982) Studies of the female sex pheromone of the native budworm, Heliothis punctigera. Entomol Exp Appl 31:395-401

Salas JJ, Ohlrogge JB (2002) Characterization of substrate specificity of plant FatA and FatB acyl-ACP thioesterases. Arch Biochem Biophys 403:25-34

Santos-Mendoza M, Dubreucq B, Baud S, Parcy F, CabocheLepiniec ML (2008) Deciphering gene regulatory networks that control seed development and maturation in Arabidopsis. Plant J 54:608-620

Schultz LD, Hofmann KJ, Mylin LM, Montgomery DL, Ellis RW, Hopper JE (1987) Regulated overproduction of the GAL4 gene product greatly increases expression from galactose-inducible promoters on multi-copy expression vectors in yeast. Gene 61:123-133

Sheen SJ (1983) Biomass and chemical composition of tobacco plants under high density growth. Beitr Tabakforsch Int 12:35-42

Simmons GS, Suckling DM, Carpenter JE, Addison MF, Dyck VA, Vreysen MJB (2010) Improved quality management to enhance the efficacy of the sterile insect technique for lepidopteran pests. J Appl Entomol 134:261-273

Schünmann PH, Llewellyn DJ, Surin B, Boevink P, De Feyter RC, Waterhouse PM (2003) A suite of novel promoters and terminators for plant biotechnology. Funct Plant Biol 30:443-452

Vanhercke T, Divi UK, Tahchy AEI, Liu Q, Mitchell M, Taylor MC, Eastmond PJ, Bryant F, Mechanicos A, Blundell C, Zhi B, Belide S, Shrestha P, Zhou XR, Ral JP, White RG, Green A, Singh SP, Petrie JR (2017) Step changes in leaf oil accumulation via iterative metabolic engineering. Metab Eng 39:237-246

Voelker TA, Hayes TR, Cranmer AM, Turner JC, Davies HM (1996) Genetic engineering of a quantitative trait: metabolic and genetic parameters influencing the accumulation of laurate in rapeseed. Plant J 9:229-241 
Weatherston I, Stewart R (2002) Regulatory issues in the commercial development of pheromones and other semiochemicals. IOBC/ WPRS Bull 25:1-10

Werner S, Breus O, Symonenko Y, Marillonnet S, Gleba Y (2011) High-level recombinant protein expression in transgenic plants by using a double-inducible viral vector. Proc Nat Acad Sci 108:14061-14066

Wyatt TD (2003) Pheromones and animal behaviour: communication by smell and taste. Cambridge University Press, Cambridge

Yan Q, Kuriyama K, Nishikawa K, Tominaga S, Tatsuta H, Ando T, Naka H (2015) Z)-13-hexadecenyl acetate: a novel moth sex pheromone component from Herpetogramma submarginale (Lepidoptera: Crambidae. J Chem Ecol 41:441-445

Yang Z, Ohlrogge JB (2009) Turnover of fatty acids during natural senescence of Arabidopsis, Brachypodium, and switchgrass and in Arabidopsis $\beta$-oxidation mutants. Plant Physiol 150:1981-1989

Publisher's Note Springer Nature remains neutral with regard to jurisdictional claims in published maps and institutional affiliations. 